\title{
SENTIMENTOS E EXPECTATIVAS DO SER-AMPUTADO: um olhar fenomenológico
}

Lilian Bitencourt Alves BARBOSA ${ }^{1}$

Cynthia Lima GUERRA ${ }^{2}$

Janaina Lamin RESENDE ${ }^{3}$

Maria Bethânia Tinti de ANDRADE ${ }^{4}$

\author{
${ }^{1}$ Mestre em Enfermagem pela Universidade Federal de Alfenas. Email: 1ballves@ hotmail.com \\ ${ }^{2}$ Enfermeira pela Universidade Federal de Alfenas. Email: cylimaguerra@yahoo.com.br \\ ${ }^{3}$ Enfermeira no Hospital Universitário da Universidade Federal de Uberlândia. Email: jlrenf@yahoo.com.br \\ ${ }^{4}$ Mestre em Enfermagem. Docente da Universidade Federal de Alfenas - MG Email: betania.andrade@ unifal-mg.edu.br
}

Recebido em: 12/10/2015 - Aprovado em: 13/07/2016 - Disponibilizado em: 18/12/2016

\begin{abstract}
RESUMO
Estudo que objetiva compreender, na perspectiva do sujeito, o significado de ter um membro amputado e suas expectativas quanto ao futuro. Trata-se de pesquisa qualitativa, segundo a trajetória fenomenológica. Foram entrevistados oito sujeitos com amputação de membro inferior, residentes em Alfenas-MG e cadastrados na Seção de Órteses e Próteses do Ambulatório Municipal Dr. Plínio do Prado Coutinho. Eles foram abordados com as questões norteadoras: Como você vive a experiência de ter um membro amputado? Quais são as suas expectativas para o futuro? Seus discursos foram gravados e transcritos. Quando agrupados, originaram duas categorias de significado: sentimentos que envolvem o ser-amputado e expectativas quanto ao futuro. Tristeza, resignação, sensação de inutilidade e desvalia, perda de autoestima e pessimismo foram os sentimentos mais frequentes. Amigos, família, religião e espiritualidade foram motivadores de adaptação. A prótese e a morte representaram as expectativas quanto ao futuro. A percepção do ser-amputado sobre si mesmo, seus limites reais e imaginários e suas esperanças devem nortear os cuidados de enfermagem, a serem dispensados de forma holística e individualizada, para que a adaptação seja positiva.
\end{abstract}

Descritores: Amputação. Emoções. Enfermagem. Reabilitação.

\section{FEELINGS AND EXPECTATIONS BE AMPUTATED: A LOOK PHENOMENOLOGICAL}

\begin{abstract}
Study that aims to understand the subject's perspective, the meaning of having a limb amputated and their expectations of the future. It is a qualitative research, a phenomenological trajectory. There were eight interviewees with lower limb amputation, living in Alfenas-MG and registered in Section Orthotics and Prosthetics of the Municipal Clinic Dr. Pliny the Prado Coutinho. They were addressed to the guiding questions: How do you live the experience of having an amputated limb? What are your expectations for the future? His speeches were recorded and transcribed. When grouped, originated two categories of meaning: feelings involving be amputated and expectations about the future. Sadness, resignation, feelings of worthlessness and helplessness, loss of self-esteem and pessimism were the most frequent feelings. Friends, family, religion and spirituality were drivers of adaptation. The prosthesis and death represented the expectations about the future. Perceived be amputated about himself, his real and imaginary boundaries and their hopes should guide nursing care, to be dispensed in a holistic and individualized way, so that adaptation is positive.
\end{abstract}

Descriptors: Amputation. Emotions. Nursing. Rehabilitation. 


\section{INTRODUÇÃO}

O corpo representa o homem e sua presença no mundo. Por ele ser valorizado por sua exterioridade, sua aparência tem grande importância (SANTANA, 2000).

A avaliação que o indivíduo faz sobre si mesmo perpassa suas concepções sobre a imagem do seu corpo e a sua autoestima, que são construídas por meio das experiências acumuladas ao longo da vida. O indivíduo, ao deparar-se com o seu corpo reduzido, experimenta uma sensação de ambigüidade, por permanecer a consciência de seu corpo inteiro de antes e por ter que acostumar-se com um novo ser, agora incompleto, exigindo a adaptação a um novo contexto de vida (SANTOS; SILVA; VILA, 2003; SANTANA, 2000).

Advém daí a dificuldade da pessoa em enfrentar a si mesmo e aos outros. Diante dessa autodestruição, é preciso grande capacidade de luta interior para que seja obtida a reformulação desejada (BOCCOLINI, 1990). É de fundamental importância que a reconstrução da imagem corporal seja positiva, pois, quando negativa e não condizente com a realidade, amplia os valores estigmatizantes e preconceituosos e alimenta os sentimentos de inferioridade, baixa autoestima, tristeza e depressão (DE BENEDETTO; FORGIONE; ALVES, 2002).

A experiência do indivíduo que vivencia a amputação é comparada ao processo de luto pela morte de alguém amado
(CAVALCANTI, 1994). O luto está classificado em quatro fases. Na primeira, de impacto ou choque, o indivíduo desconsidera ou ignora a perda e parece estar absorvendo o impacto do acontecido. Na segunda, de busca e anseio, ele tenta recuperar o objeto perdido e dispõe-se a perceber qualquer estímulo que possa sugerir a presença do mesmo. Sonhos, devaneios e dor fantasma são os mecanismos usados para negar a amputação e alcançar a reintegração corporal a partir de uma falsa percepção. A terceira fase, de desespero, caracteriza-se pela renúncia à esperança de recuperar o que foi perdido. A realidade começa a ser aceita e, por concentrar-se dolorosamente em sua perda, o enlutado fecha-se em si mesmo e o mundo lhe parece vazio. Nesse momento depressivo, está presente a insônia, a perda de interesse pelo mundo, a revolta e a agressividade. Na última fase, de readaptação, o indivíduo reorganiza seu mundo interno estabelecendo novas relações com o mundo exterior (PARKES, 1970).

Para adaptar-se a sua nova realidade e neutralizar a ansiedade diante do novo estado de seu corpo, o ser-amputado utiliza diferentes estratégias, podendo reagir agressivamente, ficar muito passivo ou isolarse. A forma mais adequada de adaptação é fazer uso de meios que satisfaçam suas necessidades internas e as exigências externas (DE BENEDETTO; FORGIONE; ALVES, 2002). Para tanto, ela precisa ser um processo 
dinâmico, progressivo e educativo, que ultrapasse a recuperação de funções perdidas ou alteradas, uma vez que se destina a pessoas que, mais do que antes, vivem em uma sociedade complexa e com exigências crescentes (PESSINI; FERRARI, 2001).

O profissional de saúde tem o papel de auxiliar o ser-amputado no enfrentamento de sentimentos negativos, trazendo-lhe o sentido de realidade, de conhecimento das suas limitações, de confiança e de estímulo às suas aspirações. Ele deve adequar as esperanças do indivíduo ao seu potencial remanescente, evitando que expectativas irreais provoquem maiores frustrações (DE BENEDETTO; FORGIONE; ALVES, 2002).

As experiências vivenciadas, durante a graduação, com pacientes que tiveram um membro amputado motivaram este estudo. Estas experiências transitaram da dependência extrema do profissional de enfermagem até a independência para o autocuidado. Por esse vivenciar, as autoras foram levadas à reflexão sobre os sentimentos experimentados pelo ser-amputado, suas influências sobre o seu comportamento e os mecanismos de adaptação utilizados.

A percepção da concepção do seramputado sobre si mesmo, seus limites reais e imaginários, além de suas perspectivas para o futuro devem nortear os cuidados de enfermagem. Eles deverão ser planejados de forma holística e individualizados, promovendo a valorização das capacidades residuais, o autoconhecimento e o apoio necessário para que a adaptação seja positiva.

Diante do exposto, este estudo tem por objetivo compreender, na perspectiva do sujeito, o significado de ter um membro amputado e suas expectativas quanto ao futuro.

\section{METODOLOGIA}

Trata-se de uma pesquisa de abordagem qualitativa, segundo a trajetória fenomenológica (MARTINS; BICUDO, 1994).

A fenomenologia propõe-se a investigar de forma direta as vivências humanas e compreendê-las, sem se prender às explicações causais ou generalizações (GRAÇAS, 2000). Nesta modalidade metodológica a generalização é abandonada e o foco da atenção é centralizado no específico, no peculiar e no individual, almejando sempre a compreensão, não a explicação dos fenômenos estudados (MARTINS; BICUDO, 1994).

$\mathrm{Na}$ análise qualitativa do fenômeno é no discurso do sujeito sobre a sua experiência vivencial que se busca a aproximação com a essência ou a estrutura do fenômeno (GRAÇAS, 2000). O alvo da investigação é descobrir como o sujeito se percebe no mundo e o sentido que ele atribui à situação pesquisada (MARTINS; BICUDO, 1994).

A trajetória fenomenológica constituise de três momentos: a descrição, a redução e 
a compreensão. Na descrição, o sujeito revela e descreve as suas percepções a respeito do que está sendo examinado. $\mathrm{Na}$ redução, o pesquisador evidencia as partes essenciais e desconsidera aquelas que não são. É preciso ler o discurso várias vezes para familiarizar-se com texto e evidenciar os significados que respondem às indagações do pesquisador. Estes constituem as unidades de significado, que consistem em frações da descrição da experiência vivida. Já, a compreensão surge junto à interpretação, por meio da qual o pesquisador busca os significados atribuídos pelo sujeito à situação vivida. A partir de então, elabora-se a construção final dos resultados, com o objetivo de apropriar-se daquilo que se estuda em sua intenção total (MARTINS; BICUDO, 1994; GRAÇAS, 2000).

Os sujeitos deste estudo foram indivíduos submetidos à amputação de membro inferior ou de parte dele; que estivessem cadastrados na seção de órteses e próteses do Ambulatório Municipal Dr. Plínio do Prado Coutinho e fossem residentes em Alfenas-MG. A preferência pelos residentes neste município deu-se pela opção das pesquisadoras em realizar as entrevistas nos domicílios, visto serem estes o mundo-vida dos sujeitos.

No cumprimento dos preceitos éticos, o projeto de pesquisa foi submetido à apreciação do Comitê de Ética em Pesquisa da Universidade Federal de Alfenas
(BRASIL, 2013). Após sua aprovação e o consentimento dos participantes, foram agendados a data e o horário das entrevistas, que foram realizadas a partir das questões norteadoras: Como você vive a experiência de ter um membro amputado? Quais são as suas expectativas para o futuro?

As entrevistas foram gravadas, mediante autorização dos sujeitos e transcritas integralmente, após a sua realização. O critério utilizado para limitar o número de entrevistas foi o momento em que a repetição das falas tornou-se freqüente.

Foram coletadas oito entrevistas e, para que o anonimato desses sujeitos fosse preservado, seus discursos foram identificados por números. Para a compreensão do fenômeno ser-amputado, utilizamos as falas que abordavam as situações vivenciadas pelos indivíduos e autores que estudam esta temática.

\section{RESULTADOS E DISCUSSÃO}

O significado de amputar um membro tem conotações únicas para cada pessoa. A partir dos discursos transcritos, foram extraídas das falas dos sujeitos as unidades que expressavam o significado de seramputado (MARTINS; BICUDO, 1994). Após o agrupamento delas, surgiram duas categorias de análise: sentimentos que envolvem o ser-amputado e expectativas quanto ao futuro. 


\section{Sentimentos que envolvem o ser-}

\section{amputado}

Ao configurarem o seu corpo como mutilado, fazem-no identificando sentimentos de tristeza, autopiedade, vergonha, desespero, irritabilidade, sensação de desvalia e inutilidade, além de ideias de aniquilamento e imagens distorcidas dessa nova realidade, por não serem mais uma pessoa completa (CAVALCANTI, 1994).

"Do jeito que eu tenho sofrido com esse problema, não é fácil. (...) Em tudo que a gente pensa é difícil. (...) É a vida não é fácil não! (...) Ai, a vida é dura. Não é qualquer um que tem paciência pra agüentar." (DISCURSO 1)

"Pra mim é uma coisa muito triste, muito triste mesmo. (...) Só estou viva, não faço nada. (...) Nossa Senhora da Aparecida, tem dia que eu não me conformo (...) depois que ele jogou a perna em cima de uma mesa lá, da onde eu estava eu via a perna lá. Eu acho que isso me deixou assim." (DISCURSO 2)

“Amputar uma parte do corpo não é fácil não; o estilo de vida muda muito. O fator psicológico influencia muito, a vida muda. A gente precisa ter uma cabeça muito boa, senão fica doido, louco de tudo. Porque precisa andar e não consegue, precisa fazer as coisas e não consegue. Isso dá um estado de nervo na gente (...) O membro de um corpo faz uma falta tremenda (...) Sou um deficiente por completo, porque falta parte do corpo." (DISCURSO 4)

A incapacidade é uma restrição resultante de uma deficiência para desempenhar uma atividade normal. Representa a objetivação da deficiência e reflete os distúrbios da pessoa das atividades essenciais à vida diária (AMIRALIAN et. al., 2000)

A execução de atividades produz prazer e satisfação de necessidades psicológicas. Com a limitação imposta pela amputação, em maior ou menor extensão, não há uma atividade completa e, portanto, não há a satisfação psicológica resultante (BOCCOLINI, 1990).

“Ah, é dureza! Não é fácil não! Porque quando a gente tem as duas pernas, é muito fácil pra gente andar, mas com uma só é difícil (...). É gostoso demais quando a gente tem a perna da gente! (...) É com tanta dificuldade, é difícil até de tomar um banho. (...) Não posso andar longe (...) tem que ficar mais é de castigo! A Igreja é aqui pertinho e eu não posso ir lá (...), pra mim consultar agora o médico tem que vim aqui, porque eu não tenho condições de ir lá, aí vai levando...(...) Eu gosto de lavar, de passar, de cozinhar e agora minha filha tem que me dar tudo na mão." (DISCURSO 1)

"Faz quatro anos que eu amputei.

Trabalhava muito, já trabalhei bastante. 
Depois aconteceu isso, eu num tinha jeito de fazer mais nada, eu fiquei meio aborrecido, meio contrariado.” (DISCURSO 5)

“...não pode andar, não pode fazer nada, tirou metade da minha capacidade. Eu podia estar andando, trabalhando, mas nem dirigir eu consigo." (DISCURSO 7)

É perceptível nos fragmentos dos discursos a preocupação com a impossibilidade de executar as atividades cotidianas. Além de estarem limitados nos cuidados com as suas famílias, passam a viver uma relação de dependência dos outros para o cuidado consigo mesmos, gerando sentimento de impotência (FERREIRA; MAMEDE, 2003).

“... eu não tenho uma perna, que jeito eu vou fazê (...) eu tive que ficar aqui (asilo) porque eu sou sozinho.” (DISCURSO 8)

“... eu sem poder andar, meu esposo na cama aí, que deu derrame e eu nem cuido dele. Eu tava cuidando e depois foi dando problemas pra mim e eu não pude mais" (DISCURSO 1)

O estado de depressão pode instalar-se como uma das fases do processo de luto, caracterizado por um estado de profundo pesar e infinita tristeza (DIOGO, 2003).

No processo de elaboração da perda, o ser-amputado encontra-se lamentando a vida. A perda do membro é vivenciada como o fim de uma vida normal, uma vez que ele tem a compreensão de sua realidade de antes e de seu estado atual (BOTELHO; VOLPINI; MOURA, 2003).

Esses estados emocionais implicam no sentimento de maior vulnerabilidade a fatores externos e de total incapacidade, devido ao seu estado pessimista (BOCCOLINI, 1990).

"Eu acho que fiquei com depressão. Isso ficou na minha cabeça até hoje, sabe. (...) Daqui pra frente eu vou ficar por conta só de beber remédio, muito remédio." (DISCURSO 2)

"Na idade que eu to, um (membro) amputado e outro pelejando pra querer amputar também, eu espero pouco da vida." (DISCURSO 7)

"Mas agora me acalmei, já estou deficiente pelo resto da vida mesmo! (...) Sou um deficiente por completo (...), portanto sou indefeso, estou sujeito a complicações a todo momento." (DISCURSO 4)

O ser-amputado pode utilizar diversas estratégias para se adaptar a realidade e neutralizar a sua ansiedade reagindo agressivamente, apresentado-se muito passivo ou isolando-se cada vez mais (DE BENEDETTO; FORGIONE; ALVES, 2002).

A resignação está baseada na crença de que não se pode fazer nada a respeito do problema que se enfrenta e que simplesmente deve conformar-se com a situação (SANTOS; SILVA; VILA, 2003). 
"Mas, fazer o que? Agora já foi, seja o que Deus quiser!” (DISCURSO 2)

"Sinto a mesma coisa, não sinto mal não, sentada aqui (apontando a cadeira de rodas) (...) Era a perna ou a vida. Resolvi." (DISCURSO 3)

“...depois pus na cabeça que Deus quis assim, tem que ficar assim, concordei. Concordei porque é difícil, concordei." (DISCURSO 5)

“...eu por mim, eu nem sei como esclarecer sabe, mais é uma realidade de vida. É o que acontece e tenho que aceitar." (DISCURSO 6)

A forma mais adequada de adaptação é buscar meios que satisfaçam as necessidades internas e as exigências do ser-amputado, utilizando formas de adaptação coerentes com a sua limitação física. Para tanto, a etapa inicial de reintegração corporal é a aceitação do seu novo estado e da necessidade de ajuda externa. O auxilio do outro pode ser encarado como negativo e indicativo de que ele é incapaz, porém quando o ser-amputado aceita a sua condição, ele percebe a importância da ajuda, sem repercussões negativas (DE BENEDETTO; FORGIONE; ALVES, 2002).

"Limpar uma casa, lavar um banheiro, lavar uma louça, eu não tenho condições, eu faço serviço é de crochê, ponto cruz, pintura, eu faço minhas coisinhas aqui (...). As outras coisas eu ajudo se for preciso." (DISCURSO
"Eu mesmo faço as coisas em casa, moro sozinho. Limpo a casa, faço comida pra mim (...) Agora, pra mim sair, tenho que arrumar alguém pra me levar e buscar." (DISCURSO 4)

"agora é viver aqui no asilo mesmo, se eu puder trabalhar, eu ajudo um pouco. O que eu posso fazer, eu faço; corto o cabelo deles, faço a barba, vou levando a vida." (DISCURSO 8)

A aceitação da perda física é necessária para que o indivíduo possa relacionar-se com os outros e consigo mesmo de forma mais produtiva e autêntica, incorporando suas limitações e pensando em estratégias eficazes para sua maior autonomia, dentro dos limites da sua deficiência (DE BENEDETTO; FORGIONE; ALVES, 2002).

Quando a perda é devidamente compreendida, a busca da adaptação se torna objetiva. Há a consciência de que o corpo tem um problema físico, mas a integridade do ser é preservada. $\mathrm{O}$ conhecimento exato da dimensão da perda é o que vai permitir a busca objetiva da adaptação.

$\mathrm{O}$ apoio dos amigos é uma fonte de suporte emocional que ajuda a pessoa que sofreu a amputação a manter sua autoconfiança e acreditar em sua melhora. Sentindo-se querido, o indivíduo tem seu sofrimento minimizado e sua auto-estima elevada (BERGAMASCO, 2001). 3) 
"Moro sozinho, mas meus amigos me ajudam muito (...) tenho muito amizade boa, vamos conversando, dando risadas e o tempo vai passando." (DISCURSO 4)

A fé em um ser superior também auxilia a superação e o enfrentamento de momentos de insegurança intensa e de sofrimento. A fé, a confiança e a esperança emergem como sentimentos positivos que amenizam e dão suporte ao confronto com o medo, a angústia e a insegurança (SANTOS; SILVA; VILA, 2003)

O homem, ao deparar-se com a enfermidade, principalmente a física, tem sua espiritualidade aguçada. A fé, por meio do objeto sagrado, acende uma chama de otimismo e a doença passa a ser compreendida como um evento casual (BATISTA, 2004).

Os sujeitos deste estudo demonstraram fé incondicional e submissão à vontade divina, cabendo-lhes a aceitação e a resignação.

"Só por Deus mesmo. Deus dá força pra gente. Ainda bem que graças a Deus eu não posso reclamar não, porque eu tenho Jesus comigo e ele me dá muita força pra passar o que eu passo. (...) pedi a Deus me dar, se fosse preciso eu operar, me dar força $e$ coragem pra quando o médico voltasse eu desse a resposta certa. (...) Deus me deu aquela força, aí operou. (...) Deus ajudou, foi indo, foi indo, sarou e aí eu passei a usar o aparelho (prótese) outra vez. Eu não podia usar o aparelho (prótese) (...), depois de tanto que a gente foi pedindo, foi orando, orando $e$ orando, Deus ajudou e sarou, agora eu posso usar. (...) Tem que estar satisfeitinho, pra Deus ter dó da gente e dar força pra gente vencer. (...) Eu tudo posso naquele que me fortalece!"” (DISCURSO 1)

"É o que acontece e tenho que aceitar, em nome de Jesus Cristo. (...) E hoje a minha saúde é controlada e eu dou graças a Deus por isso, que sempre está abençoando." (DISCURSO 6)

"Faz 4 meses que eu estou lutando com esse membro pra ver se ele salva. Se não puder, fazer o quê, é o desígnio de Deus (silêncio), tem que aceitar!” (DISCURSO 7)

\section{Expectativas quanto ao futuro}

Ao deparar-se com a doença, a instabilidade emocional e socioeconômica, o ser-amputado se desequilibra e se entrega à mercê do que há de vir. Teme a rejeição e o fato de ser visto como um inválido. "Pior do que morrer é ficar inútil, cercado de limitações, sem um expectativa concreta quanto ao futuro" (WANDERBROOCKE, 1998).

“Eu não tenho mais esperança em nada. É como se diz, agora eu só espero o dia que o Senhor me chamar, porque o futuro de agora 
pra frente não vai ter mais nada não." (DISCURSO 1)

"Agora só me resta ter calma e paciência, porque não é fácil não, viu? (...) Agora é pensar positivo, que vai dar tudo certinho." (DISCURSO 4)

A aquisição da prótese é associada à retomada da independência e do sentimento de totalidade, que devolve ao indivíduo a sua auto-estima, por meio da recuperação estética, e possibilita a sua reintegração psicológica e social (BOTELHO; VOLPINI; MOURA, 2003).

A prótese possibilita a restauração funcional do indivíduo, fazendo com que ele tenha sua independência máxima nas atividades diárias, permitindo-o viver de forma mais completa e ativa (DIOGO, 2003).

O sujeito almeja a prótese como quem aguarda a perna perdida (DE BENEDETTO; FORGIONE; ALVES, 2002).

"Outra coisa que eu espero, se Jesus me curar, pôr outra perna que eu possa caminhar pra mim poder ir na igreja, que o meu sonho é ir pra igreja, única coisa que eu gosto muito." (DISCURSO 1)

"Espero ganhar a perna mecânica pra poder ir ao supermercado sozinho, pagar minhas contas." (DISCURSO 4)

"Eu espero que melhora mais, pra mim poder andar (...). Porque andando é melhor do que ficar meio parado assim. (...) dá pra eu andar melhor, aí eu fico mais alegre ainda (risos)." (DISCURSO 5)

“... acredito que o homem vai me ajudar. A assistência social, numa entrevista que eu tive, eles pegaram meus dados e breve sei que vou receber essa prótese para andar." (DISCURSO 6)

Em situações de vulnerabilidade e de desamparo, quando os indivíduos vivenciam a precariedade da condição humana, a morte se impõe à consciência e à elaboração. A morte é compreendida pelo ser-amputado como uma fuga, uma vez que ele não tem esperança de um novo contexto de vida. A desesperança faz com que ele se desinteresse pelas pessoas e pelas atividades em geral. Ao ser dominado por pensamentos de inferioridade e de inutilidade, a morte passa a ser a única saída (SCHRAMM, 2002).

"Prefiro morrer, porque o que adianta a gente viver do jeito que eu estou vivendo.(...) mas, que eu posso esperar da vida? Não espero mais nada, só espero a morte chegar, só! Não tenho gosto pra mais nada." (DISCURSO 2)

"Eu espero morrer, o que eu vou esperar mais? Não vai melhorar nada. Não vai passar disso não. ” (DISCURSO 3)

A desistência de viver deve ser compreendida como um apelo dramático de ajuda. O sujeito amputado necessita de 
ouvintes empáticos que compreendam suas alterações de humor, que o ajudem a mobilizar mecanismos eficazes de enfrentamento e recursos individuais e familiares, no sentido de alcançar seu potencial máximo para viver com dignidade o dia-a-dia (RADUNZ, 1999).

\section{CONCLUSÃO}

A trajetória deste estudo favoreceu a compreensão do significado de ter um membro amputado e das expectativas dos entrevistados.

Tristeza, resignação, sensação de inutilidade e desvalia, perda de autoestima e pessimismo foram os sentimentos expressos com maior frequência.

Amigos, família, religião e espiritualidade foram motivadores de adaptação ao novo contexto de vida.

As expectativas quanto ao futuro mostraram-se controversas, pois, se de um lado almejam a prótese, idealizando a

\section{REFERÊNCIAS}

AMIRALIAN, M. L. T. et al. Conceituando deficiência. Rev Saúde Públ., São Paulo, v. 34, n. 1, p. 97-103, 2000.

BATISTA, M. A. Presença do sagrado em um momento crítico: internação em uma Unidade de Terapia Intensiva. Rev. bras. enferm., Brasília , v. 57, n. 5, p. 579-85, 2004.

BERGAMASCO, R. B.; ANGELO, M. O sofrimento de descobrir-se com câncer de mama: como o diagnóstico é experenciado retomada da independência e a reintegração social, do outro, acreditam ser a morte a única solução.

A aceitação e a adaptação ocorrem quando o indivíduo compreende devidamente a sua perda, incorporando suas reais limitações, pensando estratégias e alternativas eficazes para sua maior autonomia.

A percepção da concepção do seramputado sobre si mesmo, seus limites reais e imaginários, além de suas expectativas quanto ao futuro devem nortear a assistência de enfermagem. Esta deve incluir o apoio emocional, a valorização das capacidades residuais e a promoção do autoconhecimento do indivíduo, para que ele seja capaz de recobrar o amor próprio e adaptar-se de forma mais positiva, apesar da incompletude de seu corpo.

pela mulher. Rev. bras. cancerol, v. 47, n.3, p. 277-82, 2001.

BOCCOLINI, F. Reabilitação: amputados, amputações, próteses. São Paulo: Robe, 1990, $150 \mathrm{p}$.

BOTELHO, N. L. P.; VOLPINI, M.; MOURA, E. M. Aspectos psicológicos em usuários de prótese ocular. Arq. Bras. Oftalmol., São Paulo, v. 66, n. 5, p. 637-46, 2003. 
BRASIL. Conselho Nacional de Saúde. Resolução no 466, de 12 de dezembro de 2012. Diretrizes e normas regulamentadoras de pesquisa envolvendo seres humanos. Brasília, 2013.

CAVALCANTI, M. C. T. Adaptação psicossocial à amputação de membros. $J$. Bras. Psiquiatr., Rio de Janeiro, v. 43, n. 2, p. 71-4, 1994.

DE BENEDETTO, K. M.; FORGIONE, M. C. R.; ALVES, V. L. R. Reintegração corporal em pacientes amputados e dor fantasma. Acta Fisiátr., São Paulo, v. 9, n. 2, p. 35-9, 2002.

DIOGO, M. J. D. Satisfação global com a vida e determinados domínios entre idosos com amputação de membros inferiores. Rev. Panam. Salud Publ., Washington, v. 13, n. 6, p. 395-99, 2003.

FERREIRA, M. L. S. M.; MAMEDE, M. V. Representação do corpo na relação consigo mesma após mastectomia. Rev. Latino-Am. Enfermagem, Ribeirão Preto, v. 11, n. 3, p. 299-304, 2003.

GRAÇAS, E. M. Pesquisa qualitativa e a perspectiva fenomenológica: fundamentos que norteiam sua trajetória. Rev. Min. Enf., Belo Horizonte, v. 4, n. 1, p. 28-33, 2000.

MARTINS, J.; BICUDO, M. A. V. A pesquisa qualitativa em psicologia: fundamentos e recursos básicos. 2. ed. São Paulo: Morais, 1994. 110 p.

PARKES, C. M. Seeking end finding lost object: evidence from recent studies of the reaction to bereavement. Soc. Sci. Med., Amsterdã, v.4, p. 187-201, 1970.

PESSINI, L.; FERRARI, M. A. C.

Reabilitação, qualidade de vida e inclusão social: questões básicas à cidadania. $O$ Mundo da Saúde, São Paulo, v. 25, n. 4, p. 349-50, 2001.

RADUNZ, V. A. Cuidando e se cuidando. 2 ed. Florianópolis: AB, 1999.

SANTANA, M. G. Áreas de silêncio e corpo diabético. Rev. bras. enferm., Brasília, v. 53, n. 1, p. 95-8, 2000.

SANTOS, A. N. S.; SILVA, F. L.; VILA, V. S. C. O significado da mastectomia radical modificada: só quem faz é que sabe. Nursing, São Paulo, v. 61, n. 6, p. 30-5, 2003.

SCHRAMM, F. R. Morte e finitude em nossa sociedade: implicações no ensino de cuidados paliativos. Revista Brasileira de

Cancerologia, Rio de Janeiro, v. 48, n. 1, p. 17-20, 2002.

WANDERBROOCKE, A. C. N. S. Aspectos emocionais do paciente ostomizado por câncer: uma opção pela vida. Cogitare enferm., Curitiba, v. 3, n. 1, p. 21-3, 1998. 